\title{
The cost of first-ever stroke in Valle d'Aosta, Italy: linking clinical registries and administrative data
}

\author{
Edo Bottacchi ${ }^{1 *}$, Giovanni Corso ${ }^{1}$, Piera Tosi ${ }^{1}$, Massimo Veronese Morosini ${ }^{2}$, Giuseppe De Filippis ${ }^{3}$, Laura Santoni ${ }^{4}$,
} Gianluca Furneri ${ }^{5}$ and Cristina Negrini ${ }^{6}$

\begin{abstract}
Background: Stroke is one of the most relevant reasons of death and disability worldwide. Many cost of illness studies have been performed to evaluate direct and indirect costs of ischaemic stroke, especially within the first year after the acute episode, using different methodologies.

Methods: We conducted a longitudinal, retrospective, bottom-up cost of illness study, to evaluate clinical and economic outcomes of a cohort of patients affected by a first cerebrovascular event, including subjects with ischaemic, haemorrhagic or transient episodes. The analysis intended to detect direct costs, within 1,2 and 3 years from the index event. Clinical patient data collected in regional disease registry were integrated and linked to regional administrative databases to perform the analysis.

Results: The analysis of costs within the first year from the index event included 800 patients. The majority of patients (71.5\%) were affected by ischaemic stroke. Overall, per patient costs were $€ 7,079$. Overall costs significantly differ according to the type of stroke, with costs for haemorrhagic stroke and ischaemic stroke amounting to $€ 9,044$ and $€ 7,289$. Hospital costs, including inpatient rehabilitation, were driver of expenditure, accounting for $89.5 \%$ of total costs. The multiple regression model showed that sex, level of physical disability and level of neurological deficit predict direct healthcare costs within 1 year. The analysis at 2 and 3 years (per patient costs: $€$ 7,901 and $€ 8,874$, respectively) showed that majority of costs are concentrated in the first months after the acute event.

Conclusions: This cost analysis highlights the importance to set up significant prevention programs to reduce the economic burden of stroke, which is mostly attributable to hospital and inpatient rehabilitation costs immediately after the acute episode. Although some limitation typical of retrospective analyses the approach of linking clinical and administrative database is a power tool to obtain useful information for healthcare planning.
\end{abstract}

Keywords: Stroke, Costs, Italy, Prevention, Administrative claims, Record linkage

\section{Background}

The traditional definition of a stroke, [1], is "a neurological deficit of cerebrovascular cause that persists beyond 24 hours or is interrupted by death within 24 hours". Worldwide, stroke is one of the most common causes of death, long-term morbidity and disability [2-4]. Annually, 15 million people worldwide suffer a stroke [5]. Of these, 5 million die and another 5 million are left permanently disabled, placing a burden on family and community. Moreover, due to the progressive population ageing, the absolute number of

\footnotetext{
* Correspondence: ebottacchi@ausl.vda.it

'Department of Neurology, Regional Hospital of Aosta Valley, Aosta, Italy Full list of author information is available at the end of the article
}

stroke incidence is expected to increase. By 2030, stroke would be the leading cause of $10.4 \%$ and $11.8 \%$ of male and female annual deaths, respectively [6].

Owing to the high level of morbidity associated with stroke, the economic burden of this disease is substantial. For 2008, it was estimated that stroke would cost the US economy \$ 65.5 billion in healthcare services, medications, and lost productivity [7].

Stroke can be classified into two major categories: ischaemic and haemorrhagic. Ischaemic stroke is caused by an interruption of the blood supply, while haemorrhagic stroke results from a rupture of a blood vessel or an abnormal vascular structure. $87 \%$ of strokes are

\section{() Biomed Central}


caused by ischemia and the remainder by haemorrhage [8].

Many international [9-19] and national [20,21] studies have estimated healthcare costs and resource utilization associated with ischaemic stroke, particularly those costs and hospitalizations that arise from nonstroke-related cardiovascular events in the post-stroke follow-up period. Conversely, there is still poor information on the economic burden of haemorrhagic stroke.

Cost-of-illness (COI) analysis is the main method of providing an overall view on the economic impact of a disease [22]. In Italy, two different studies have evaluated the economic burden of stroke in Italy, using various approaches. Gerzeli et al., in the ECLIPSE study [20], evaluated direct and indirect costs of stroke using a longitudinal, incidence-based methodology. Morsanutto et al. [21] estimated cost and outcomes after first stroke hospital admission using administrative databases.

Region Valle d'Aosta owns a large informative system on administrative patients' claims, collecting records on healthcare services offered to the resident population (prescriptions, ambulatory interventions, hospitalizations). In the same timeframe the Regional Valle d'Aosta Hospital has set up a stroke clinical registry, including patients who have been hospitalized since 1 January 2004 to date. The main purpose of the present study is to link the two clinical and administrative sources in order to: 1) estimate the current burden of stroke in Valle d'Aosta; 2) evaluate the risk of death and of further hospitalization due to cardio-cerebrovascular reason; 3) evaluate the annual costs of stroke comparing the costs according to the type of cerebrovascular event; 4) assess the contribute of each cost component on total annual costs; 5) determine the relation between costs, demographic and clinical status of patients with stroke.

\section{Methods}

\section{Study design}

The present study is a longitudinal, retrospective, bottom-up cost of illness study, aimed to evaluate clinical and economic outcomes of a cohort of patients affected by a first cerebrovascular event (stroke or transient ischaemic attack, TIA). The analysis is conducted in the perspective of the Italian regional healthcare system: only direct costs have been evaluated. In the main analysis, patients who were hospitalized for a cerebrovascular accident, included in the disease clinical registry, matching inclusion criteria, were observed up to 1 year after hospital admission or death, whichever came first. The date of hospital admission was the index date and coincided with the beginning of observation. Dates of death and/or next hospitalizations due to cardiocerebrovascular event, if applicable, were detected through record linkage between the clinical registry, the demographic database and the hospitalization database, respectively. Economic resources used by patients were detected through record linkage between regional administrative healthcare archives and the clinical registry (Figure 1). Cerebrovascular-related resource consumption data on hospitalizations, pharmaceutical prescriptions, ambulatory interventions (also including patients' rehabilitation), after index date were collected. Additional analyses were performed to assess clinical outcomes and costs over a period of two and three years.

\section{Data sources}

Data from different sources were integrated through database linkage and then used to conduct the analysis: 1) data included in the clinical disease registry; 2) administrative data on demographic status of the Val d'Aosta resident population; 3) data on pharmaceutical prescriptions; 4) data on ambulatory and specialistic visits; 5) data on

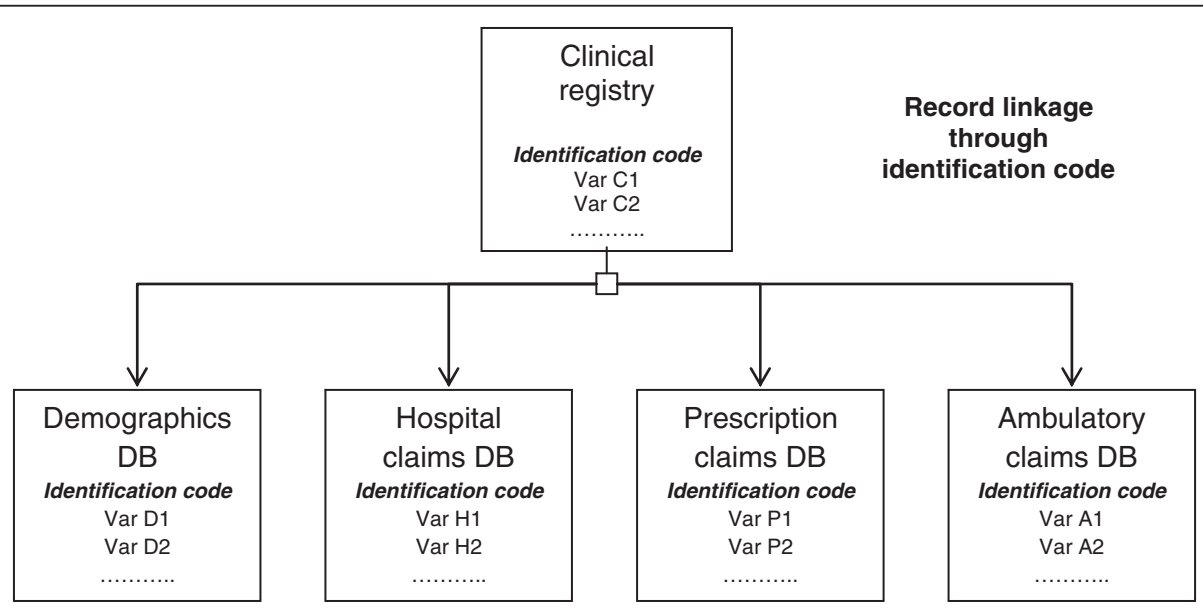

Figure 1 Structure of database linkage*. 
Table 1 Reasons for exclusion criteria

\begin{tabular}{lcc}
\hline Exclusion criteria* & No. of patients excluded & (\%) \\
\hline Index date not allowing a 365 days - observation period & 362 & $(45.3 \%)$ \\
\hline Previous major cerebrovascular event & 272 & $(34.0 \%)$ \\
\hline Venous trombo-embolism & 1 & $(<1.0 \%)$ \\
\hline Age $<18$ years & 1 & $(<1.0 \%)$ \\
\hline
\end{tabular}

* Patients can have more than one exclusion criteria at the same time.

hospitalizations. Data from datasets 1, 2, 4 and 5 covered the period between January 1, 2004 and December 31, 2007. Data from dataset 3 covered the period between January 1, 2003 and December 31, 2007.

As sensitive patients' information was stored in data sources, the present study was submitted to the Ethical Committee of Aosta LHU, which approved it. Also, in order to assure patients' privacy, identification codes used in both administrative databases and clinical registries were preliminary transformed into alphanumeric codes, so that researches could not have access to sensitive data.

\section{Inclusion and exclusion criteria}

To be included in the analysis, subjects must be recorded in the disease clinical registry, collecting all hospital admissions due to cerebrovascular disease

Table 2 Sample characteristics: demographic variables

\begin{tabular}{lll}
\hline Variable & 800 & $(100 \%)$ \\
\hline Total patients - No $(\%)$ & & $(48.6 \%)$ \\
\hline Sex - No. $(\%)$ & 389 & $(51.4 \%)$ \\
\hline Male & 411 & \\
\hline Female & & $(4.0 \%)$ \\
\hline Class of age - No (\%) & 32 & $(15.0 \%)$ \\
\hline$<45$ years & 120 & $(22.0 \%)$ \\
\hline $45-64$ years & 176 & $(38.6 \%)$ \\
\hline $65-74$ years & 309 & $(20.4 \%)$ \\
\hline $75-84$ years & 163 & $( \pm 13.5)$ \\
\hline 85 years & 74.9 & $(100 \%)$ \\
\hline Age, years - Mean $( \pm$ SD) & & $(2.8 \%)$ \\
\hline Job activity - No $(\%)$ & 795 & $(<1.0 \%)$ \\
\hline Total number of patients & 22 & $(84.0 \%)$ \\
\hline Housewife & 1 & $(12.2 \%)$ \\
\hline Not occupied & 675 & $(100 \%)$ \\
\hline Retired & 97 & $(4.9 \%)$ \\
\hline Employed & $79.4 \%)$ \\
\hline Life conditions - No $(\%)$ & 39 & \\
\hline Total number of patients & 194 & \\
\hline Lives in community & 562 & \\
\hline Lives alone & & \\
\hline Lives with others (family) & & \\
\hline
\end{tabular}

(confirmed stroke or TIA) occurred in the period January 1, 2004, December 31, 2007. The following subjects were excluded: 1) subjects with invalid demographic status at the index date (resulting as not resident or emigrated); 2) subjects who were not present in the database of hospital records (invalid database linkage); 3) subjects aged < 18 years; 4) subjects with previous documented stroke; 4) subjects not potentially observable for 1 year (index date after January 1, 2007). Patients with history ischemic transient attack (TIA) were not excluded in the analysis, as it was considered a risk factor for major cerebrovascular events (as well as other conditions like myocardial infarction, atrial fibrillation, etc.). Patients who, at the last day of observation, were alive but did not reach 1 year of follow-up, were excluded from the analysis in order to avoid overestimation of annual costs (complete followup period is not possible, and patients could generally use higher amount of resources during first months after disease onset).

\section{Clinical and economic outcomes estimation}

The demographic and clinical characteristics of the sample population were obtained from the clinical registry, which collected detailed information of social status, job, clinical and pharmacological anamnesis, status of the disease at hospital admission. In particular, Barthel Index [23] and NIHSS (National Institute of Health Stroke Scale) [24] scores were collected to estimate the level of physical dependency and the level of neurological deficit, respectively.

Survival analysis was conducted using the Kaplan-Meier method, to estimate time to death and time to fatal or non-fatal cardio-cerebrovascular event for the sample population, over the follow period. In the analysis of time to fatal and non-fatal event, a patient was supposed to have a failure if resulted either dead or if he had hospital admission with at least one of the following ICD-9 [25] (International Statistical Classification of Diseases and Related Health Problems, $9^{\text {th }}$ Revision) diagnoses: 43X.XX (cerebrovascular diseases), 342.XX (hemiplegia and hemiparesis), 410.XX, 411.XX, 413.XX, 414.XX (myocardial infarction, angina pectoris, other ischaemic diseases), 424.XX, 426.XX, 427.XX, 428.XX (myocardial diseases, conduction disturbances, arrhythmia and heart failure), 785.XX, 780.0X, 784.3X, 784.5X (alterations and 
Table 3 Sample characteristics: clinical variables

\begin{tabular}{|c|c|c|}
\hline Variable & & \\
\hline Total patients - No (\%) & 800 & $(100 \%)$ \\
\hline \multicolumn{3}{|l|}{ Type of stroke - No (\%) } \\
\hline Ischaemic & 572 & (71.5\%) \\
\hline Haemorrhagic & 96 & $(12.0 \%)$ \\
\hline TIA (Transient ischaemic attack) & 113 & $(14.1 \%)$ \\
\hline Undetermined & 19 & $(2.4 \%)$ \\
\hline \multicolumn{3}{|l|}{ Comorbidities and risk factors - No (\%) } \\
\hline Previous myocardial infarction & 88 & $(11.0 \%)$ \\
\hline Diabetes & 141 & $(17.6 \%)$ \\
\hline Hypertension & 611 & (76.4\%) \\
\hline Dyslipidemia & 202 & (25.3\%) \\
\hline Smoke & 124 & $(15.5 \%)$ \\
\hline Familiarity for CV diseases & 77 & $(9.6 \%)$ \\
\hline Previous TIA & 53 & $(6.6 \%)$ \\
\hline Atrial fibrillation & 129 & $(16.1 \%)$ \\
\hline Heart failure & 56 & $(7.0 \%)$ \\
\hline \multicolumn{3}{|l|}{ Body mass index $\left(\mathrm{Kg} / \mathrm{m}^{2}\right)$} \\
\hline No (\%) & 592 & $(100.0 \%)$ \\
\hline Mean $( \pm$ SD) & 25.1 & (3.8) \\
\hline \multicolumn{3}{|c|}{ Level of disability measured with Barthel Index at admission } \\
\hline No (\%) & 790 & $(100.0 \%)$ \\
\hline Totally independent $(0-20)$ & 133 & $(16.8 \%)$ \\
\hline Minimally dependent (21-60) & 8 & $(1.0 \%)$ \\
\hline Moderately dependent (61-90) & 229 & (29.0\%) \\
\hline Severely dependent (91-99) & 184 & (23.3\%) \\
\hline Totally dependent (100) & 236 & (29.9\%) \\
\hline \multicolumn{3}{|c|}{ Level of neurological deficit measured with National Institutes of Health Stroke Scale (NIHSS) at admission } \\
\hline No (\%) & 790 & $(100.0 \%)$ \\
\hline No neurological deficit (NIHSS=0) & 83 & $(10.5 \%)$ \\
\hline Light neurological deficit (NIHSS=1-7) & 449 & $(56.8 \%)$ \\
\hline Moderate neurological deficit (NIHSS=8-14) & 110 & (13.9\%) \\
\hline Severe neurological deficit (NIHSS $\geq 15$ ) & 148 & $(18.7 \%)$ \\
\hline
\end{tabular}

disturbances of the nervous system, attributable to cerebrovascular accident). Patients were censored either if emigrated (or temporary transferred) within the observation period, or at the end of the observation period.

Economic resources consumed during the observation period were collected from regional administrative databases. For each of the patients recorded in the disease clinical registry, healthcare interventions occurred within the observation period were collected. We collected economic resources which were directly attributable to the cerebrovascular event: 1) drugs used for cardiocerebrovascular prevention (anti-thrombotic agents, antidiabetes agents, anti-hypertension agents, lipid-lowering drugs; 2) hospitalizations due to cardio-cerebrovascular events (according to the above mentioned classification);
3) routine ambulatory procedures for stroke patients, defined by investigators, including rehabilitation costs.

Two different cost of illness indicators were calculated: 1 ) the average yearly patient cost (regardless of observation time, which could be $<365$ days if the patient died before the end of the observation period), and 2) the cost per patient per year, which was calculated by dividing the overall amount of costs (sum of patient costs) during the year after the index date by the overall time of observation (sum of patient observation times). In addition, the average contribute of each cost component was evaluated.

Finally, two different analyses were performed to test cost differences among homogenous groups of patients. In the first analysis, we compare resource consumptions over by different forms of cerebrovascular diseases (ischaemic 


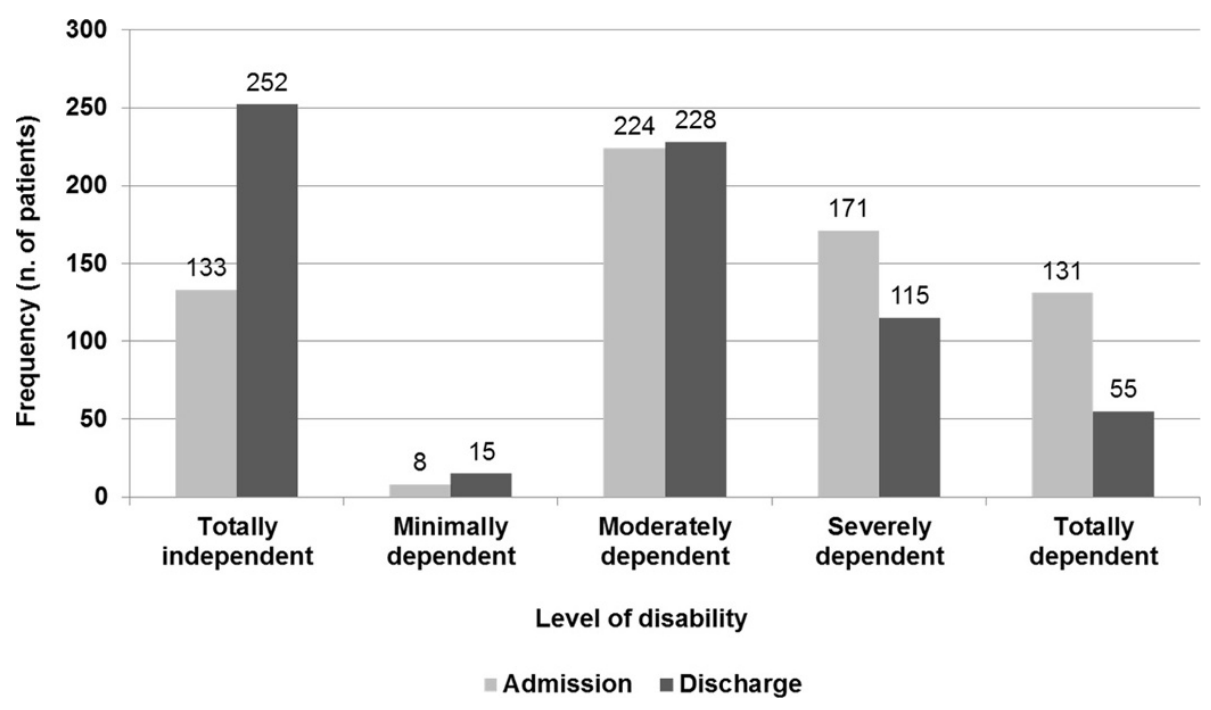

Figure 2 Distribution of patients according to Barthel index at hospital admission and discharge $(n=667)$.

stroke, haemorrhagic stroke, undetermined stroke, TIA), level of physical disability and neurological deficit. In the second analysis, we evaluated the relation between overall costs and age, sex, type of stroke, level of disability, level of neurological deficit, previous cardiovascular disease and observation time (analysis of predictors).

\section{Statistical analysis}

Analyses of socio-demographic status of the sample, clinical conditions prior to the index event, level of disease severity at hospital admission, as well as survival analyses were purely descriptive. As regards the cost analyses, two different approaches were adopted. Univariate (parametric and non-parametric) analysis was used to compare annual costs by stroke type, physical disability, neurological deficit, while Generalized Linear Model (GLM) with log link and inverse Gaussian family was used to study the relation between costs and independent variables. This methodological approach has been extensively used in predicting costs in recent [26-29].

\section{Results}

\section{Analysis at 1 year}

Overall, $800(58.0 \%)$ of 1,380 patients included in the registry were included in the analysis. Reasons of exclusion are shown in Table 1. 272 patients (19.7\%) having a previous diagnosis of major cerebrovascular disease, were excluded from the sample. Tables 2 and 3

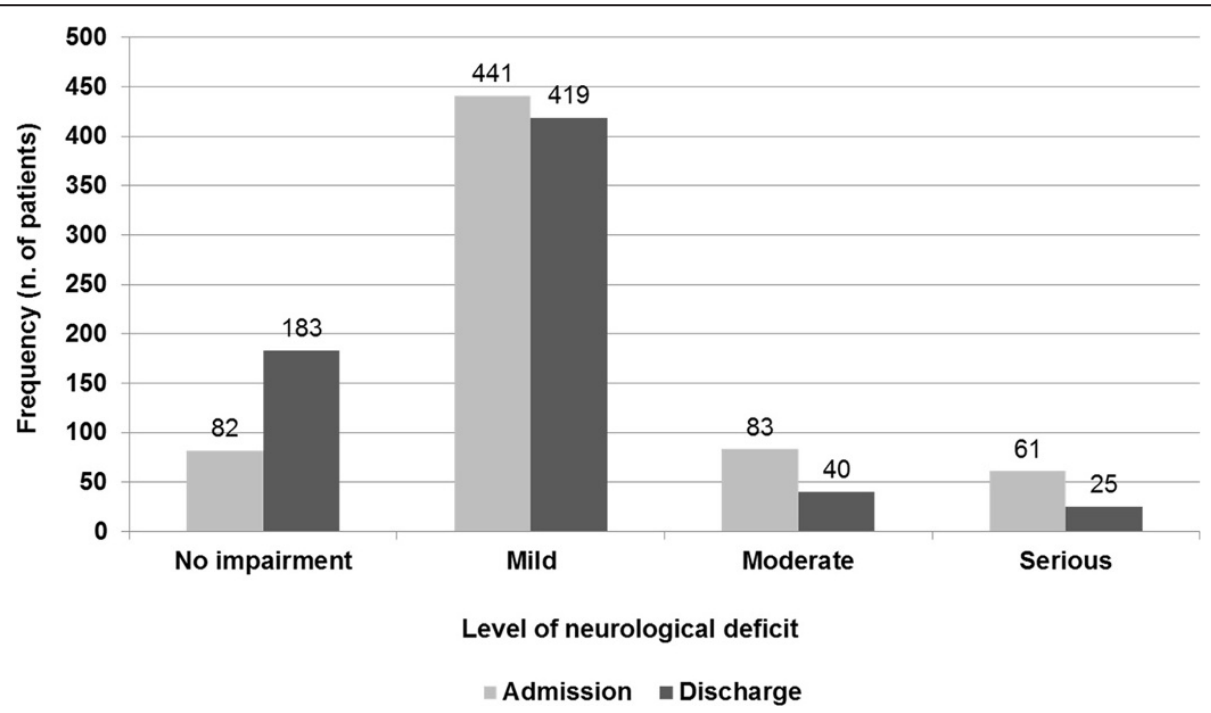

Figure 3 Distribution of patients according to NIHSS scores at hospital admission and discharge ( $n=667)$. 


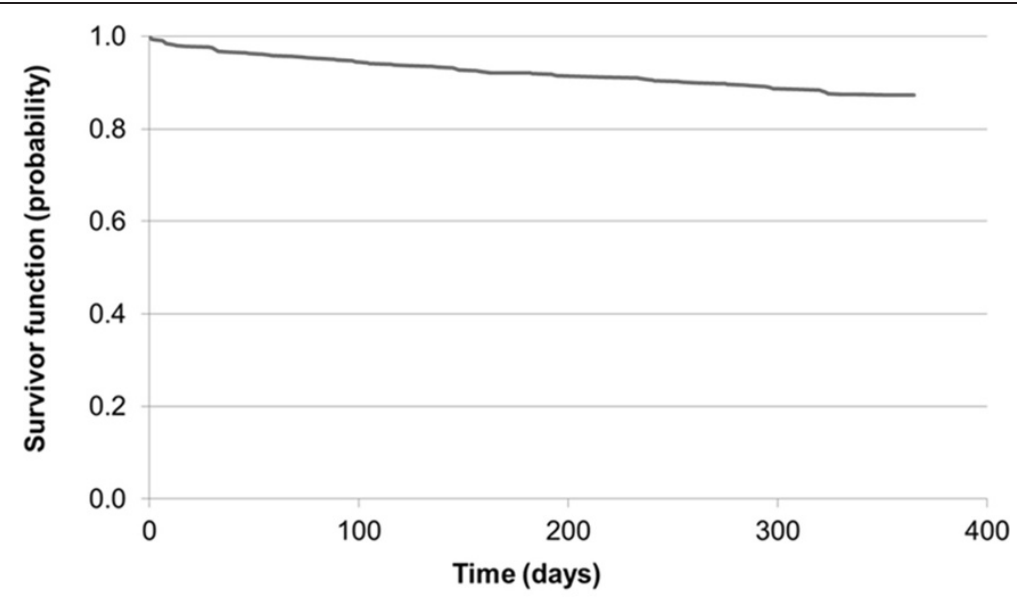

\begin{tabular}{lrrrr} 
Time (days) & 0 & 120 & 240 & 360 \\
\hline Number at risk & 686 & 643 & 622 & 598 \\
Failures & 0 & 43 & 21 & 24
\end{tabular}

Figure 4 Kaplan-Meier survival analysis to determine time to death.

summarize the main demographic and clinical characteristics of the sample, respectively. The mean age was 74.9 years (SD: \pm 13.5 ) and the sample was equally distributed between males and females $(48.6 \%$ and $51.4 \%$, respectively). The majority of patients $(n=572,71.5 \%$ of overall sample) was affected by confirmed ischaemic stroke, while haemorrhagic stroke occurred in 96 cases (12.0\%). 19 cases $(2.4 \%)$, for whom it was not possible to clearly determine the form of stroke, were defined as "undetermined". 88 (11.0\%) patients were previously affected by myocardial infarction. The most frequent risk factor among the sample population was hypertension, diagnosed in $76.4 \%$ of patients prior to index date. 141 (17.6\%) and $202(25.3 \%)$ subjects were also affected by diabetes and dyslipidemia, respectively. The average length of stay of the hospitalization determining the cerebrovascular event was 16.6 days (SD: \pm 18.2 ).

At admission, $53.2 \%$ of patients showed a moderate to severe level of disability, measured with Barthel Index (score between 91 and 100). However, in those 667

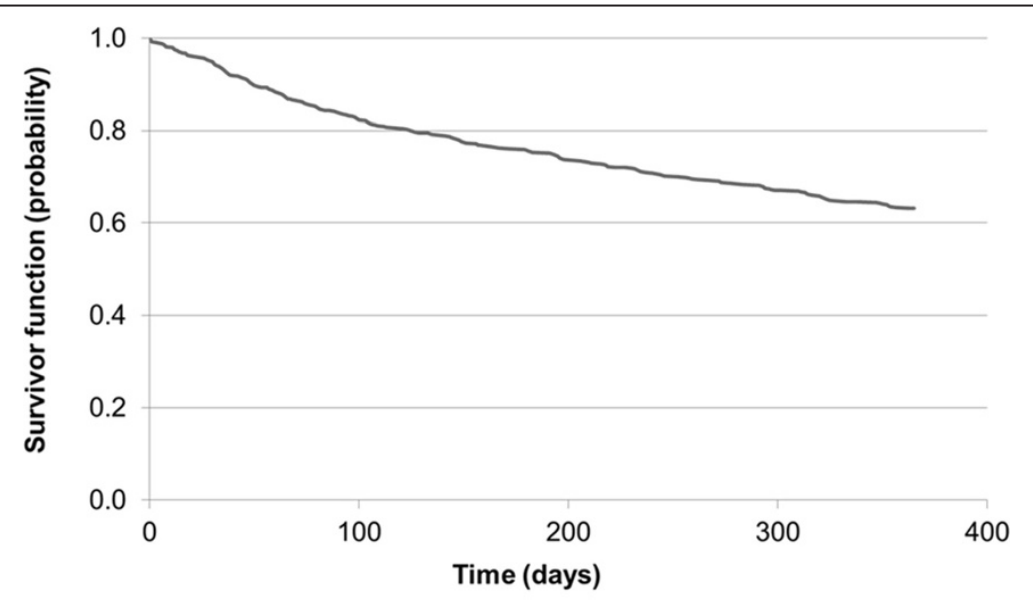

\begin{tabular}{lrrrr} 
Time (days) & $\mathbf{0}$ & $\mathbf{1 2 0}$ & $\mathbf{2 4 0}$ & $\mathbf{3 6 0}$ \\
\hline Number at risk & 684 & 551 & 485 & 433 \\
Failures & 0 & 133 & 66 & 52
\end{tabular}

Figure 5 Kaplan-Meier survival analysis to determine time to death or fatal or non-fatal cardio-cerebrovascular event. 
subjects with Barthel index measured both at admission and at discharge, a significant reduction of the disability level was observed (Figure 2, chi-square test, $\mathrm{p}<0.001$ ). As regards the neurological deficit, $32.6 \%$ of patients showed a moderate to serious level of disability. However, similarly to physical disability, a significant improvement of neurological status was observed at the end of hospitalization (Figure 3, chi-square test, $\mathrm{p}<0.001$ ).

Of the 800 patients, 114 (14.3\%) died during hospital staying, while other $88(11.0 \%)$ died within the first year after index date. Overall, about 13 deaths per 100 patients per year occurred. Figure 4 shows survival function for the 686 patients who were discharged alive after cerebrovascular event. In this cohort, survival probabilities were $92.1 \%$ and $87.2 \%$, at 180 days and 360 days after the index date. Figure 5 shows the Kaplan-Meier estimation of time to fatal or non-fatal cardio-cerebrovascular events. In the first 365 days following the index date, 252 of 684 subjects included in this analysis (36.8\%) died or had cardio-cerebrovascular event. The risk of death or non-fatal cardio-cerebrovascular accident in the first 6 months after the index date was approximately $25 \%$.

After 1 year of observation, the overall cost per patient was $€ 7,079$. Distribution of average costs per patients was asymmetric, with a median value of $€ 4,580$. During the first year of observation, the overall healthcare expenditure was $€ 5,663,259$. This expenditure was generated in 231,013 overall days of follow up (about 289 days per patient observed), resulting in $€ 8,498$ per patient per year of observation (approximately $€ 24.5$ per patient per day). Table 4 shows the cost composition from discharge to year of follow-up. Hospital costs $(€ 6,340)$ represent the main driver of expenditure, accounting for $89.5 \%$ of the total direct costs (these costs also include inpatient rehabilitation costs, which could not be separated from management costs for the acute event). Costs for outpatient rehabilitation were $40.1 \%$ of the ambulatory costs (total: $€ 164$ per patient). The average per patient cost was sensibly different according to survival time: as expected, patients surviving $\geq 30$ days $(\mathrm{n}=669)$ costs $€ 7,531$, respect to patients surviving $<30$ days or dead during hospital staying $(\mathrm{n}=131 ; € 4,770)$. As shown in Table 5, the frequency of anti-thrombotic agents, antihypertension drugs was above $75 \%$ among patients surviving $\geq 30$ days after the index date. In the same group, almost all patients $(96.3 \%)$ had at least an access for ambulatory services (diagnostic tests, laboratory analysis, physician visits, etc.).

Analysis of variance in univariate analyses showed a statistically significant difference $(\mathrm{p}<0.0001)$ of costs by type of stroke (Figure 6). This trend was also confirmed through non-parametric tests Fischer tests, evaluating the different distribution of cost quartiles among the groups $(\mathrm{p}<0.0001)$.
Table 4 Composition of average, per patient annual costs Type of costs

\begin{tabular}{lll}
\hline Total costs, $€(\%$ on total costs) & $\mathbf{7 , 0 7 9}$ & $(\mathbf{1 0 0} \%)$ \\
\hline Hospital costs, $€(\%$ on total costs) & $\mathbf{6 , 3 4 0}$ & $(\mathbf{8 9 . 5} \%)$ \\
\hline Ambulatory costs, $€(\%$ on total costs) & $\mathbf{4 0 9}$ & $\mathbf{( 5 . 8} \%)$ \\
\hline Specialistic visits & 72 & $(17.6 \%)$ \\
\hline Instrumental tests & 72 & $(17.6 \%)$ \\
\hline Laboratory analyses & 99 & $(24.2 \%)$ \\
\hline Rehabilitation & 164 & $(40.1 \%)$ \\
\hline Other & 2 & $(0.5 \%)$ \\
\hline Drug costs, $€(\%$ on total costs) & $\mathbf{3 3 0}$ & $(\mathbf{4 . 7} \%)$ \\
\hline Anti-thrombotic drugs & 43 & $(13.0 \%)$ \\
\hline Anti-hypertension drugs & 208 & $(63.0 \%)$ \\
\hline Anti-diabetes drugs & 26 & $(7.9 \%)$ \\
\hline Lipid-lowering drugs & 53 & $(16.1 \%)$ \\
\hline
\end{tabular}

Similar statistical results were achieved analyzing costs by level of physical disability at hospital discharge (totally independent: $€ 5,192.4$; minimally dependent: $€ 5,108.9$; moderately dependent: $€ 7,306.9$; severely dependent: $€ 10,461.5$; totally dependent: $€ 12,702.4)$ and level of neurological deficit (no neurological deficit: $€ 4,926.7$; light neurological deficit: $€ 7,327.3$; moderate neurological deficit: $€ 15,546.7$; severe neurological deficit: $€ 15,204.9)$.

Finally, a generalized linear regression was elaborated to study the relation between costs (dependent variable), demographic and clinical variables (independent variables). The log-link model successfully met diagnostic tests (Pearson correlation test: 0.6277, Pregibon link test: 0.7963, modified Hosmer and Lemeshow: 0.8811; p $>0.05$ values allowing analysis requirements). The modified-Park test suggested the usage of the inverse Gaussian family function (according to which variance is proportional to the cube of the mean). As shown in Table 6, the generalized model indicates that sex, level of neurological deficit (measured with NIHSS) and level of disability (measured with Barthel index) affected overall annual costs. Unlike univariate analysis, type of stroke was not found to influence annual costs. Other demographic and clinical variables (age, previous myocardial infarction, length of follow

Table 5 Frequency of resource usage in the $\geq \mathbf{3 0}$ days survivors $(n=669)$

\begin{tabular}{lll}
\hline Type of resource & & \\
\hline Hospitalization - No (\%) & 669 & $(100 \%)$ \\
\hline Ambulatory care & 644 & $(89.5 \%)$ \\
\hline Anti-thrombotic drugs & 516 & $(77.1 \%)$ \\
\hline Anti-hypertension drugs & 531 & $(79.4 \%)$ \\
\hline Anti-diabetes drugs & 100 & $(14.9 \%)$ \\
\hline Lipid-lowering drugs & 165 & $(24.7 \%)$ \\
\hline
\end{tabular}




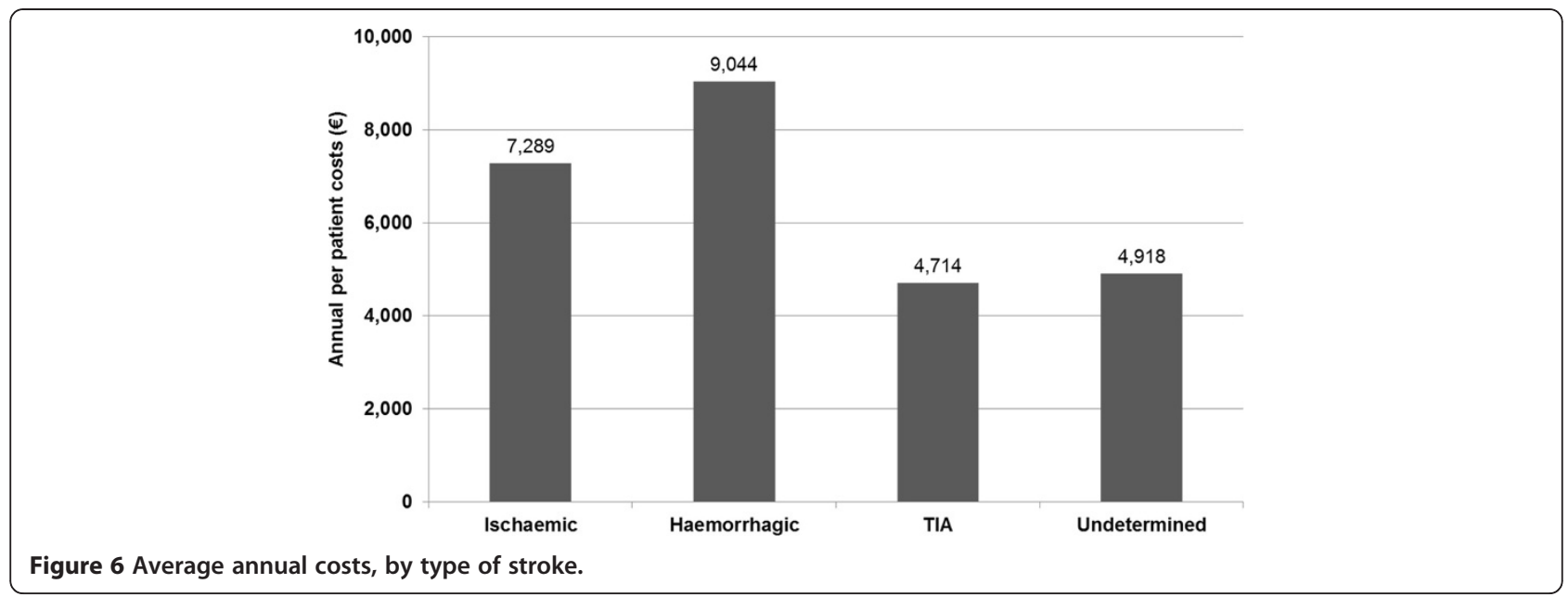

up) did not significantly predict cost variability. Generally, patients with moderate and severe neurologic impairment cost $105 \%$ and $96 \%$ more than patients without neurologic impairment, and patients with moderate and high level of disability (severely or totally dependent) cost $27 \%$ and $52 \%$ more than patients without physical disability.

\section{Analysis at 2 and 3 years}

The analysis at 2 years included 549 patients. 655 of the initial 1,380 (47.1\%) subjects were excluded from the analysis since they could not be observed for at least 2 years (index date prior to January 1, 2006). Most demographic (age, sex) and clinical characteristics of the sample (distribution by type of stroke, Barthel Index, NIHSS scores) were not different from the sample observed in 1-year analysis. The overall death risk at the end of the second year of observation was $21 \%$, while the risk of death or non-fatal cardio-cerebrovascular event for the same period was $47 \%$. The overall per patient cost in the first two years from index date was $€ 7,901$ (median: $€ 5,114$, Figure 7), with hospital costs remaining the main cost driver, accounting for $84.8 \%$ of total costs.

Subjects eligible for the analysis at 3 years were 268 . As well as in the analysis at 3 years, demographic and clinical average values and distribution remain quite similar. Kaplan Meier survival analysis showed a risk of death or non-fatal cardio-cerebrovascular accident of $29 \%$ and $59 \%$ at the end of year 3 from index date, respectively. The overall costs during the 3 years amounted to $€ 8,874$ (median: $€ 5,670$, Figure 7).

\section{Discussion and conclusion}

The present cost of illness analysis is an example of integration of two informative sources (clinical and administrative data) providing complementary information. Many cost of illness studies [30-34] have been conducted using administrative claims. Although suitable as approach for evaluating direct healthcare costs, pure administrative database analysis shows some limitations. First, such analyses cannot capture indirect costs (i.e. loss of productivity), therefore are not suitable to conduct cost of illness analyses in the society perspective. Second, characterization of sample population is often poor and based on assumptions. Both clinical and sociodemographic information (i.e. severity of the disease, level of disability, comorbidities, job, social status, etc.) are not available and this makes studies from administrative databases hardly usable for inferential analysis. On the other hand, perspective, observational economic studies are designed to clearly match objectives defined in the study protocol. However, longitudinal, perspective studies are time consuming and their implementation requires large economic. In many cases, data collection is made through questionnaires which are directly administered to the patients. This approach is not always reliable and could generate mistakes and incompleteness of results.

The approach used in the present study intends to overcome the typical drawbacks of administrative database analyses. The integration with a clinical registry allows a detailed characterization of the patient at the index date. The inclusion of incident patients assures homogeneous evaluation of costs, and the characterization type of cerebrovascular event at baseline permits to obtain information on forms such as haemorrhagic stroke, which has been less frequently evaluated by health economists. Demographic and clinical characterization was also useful to run cost prediction models. Statistical results (level of correlation, adjusted R-squared) show similar findings of the model elaborated by Gerzeli et. al [20] in their longitudinal analysis.

Cost of stroke within the first year of occurrence is concerning. A patient affected by first stroke episode costs, on average, €24.5 per day. Observed daily costs are increasingly higher for increasing level of physical 
Table 6 Results of the generalized linear model analysis

\begin{tabular}{|c|c|c|c|c|}
\hline \multirow[t]{2}{*}{ Variables } & \multirow[t]{2}{*}{$\operatorname{Exp}(b)$} & \multicolumn{2}{|c|}{ 95\% Confidence interval } & \multirow{2}{*}{$\begin{array}{l}P \\
\text { value }\end{array}$} \\
\hline & & Lower limit & Upper limit & \\
\hline \multicolumn{5}{|l|}{ Sex } \\
\hline Female & Reference & & & \\
\hline Male & 1.174949 & 1.057331 & 1.305651 & 0.003 \\
\hline \multicolumn{5}{|l|}{ Age (quartiles) } \\
\hline First quartile (20.3-68.1 yrs) & Reference & & & \\
\hline Second quartile (68.3- 77.5 yrs) & 1.016946 & 0.882974 & 1.171244 & 0.816 \\
\hline Third quartile (77.5-83.9 yrs) & 0.987269 & 0.851009 & 1.145346 & 0.866 \\
\hline Fourth quartile (83.9-98.7 yrs) & 0.850884 & 0.718406 & 1.007793 & 0.061 \\
\hline \multicolumn{5}{|l|}{ Type of stroke } \\
\hline Ischemic stroke & Reference & & & \\
\hline Hemorrhagic stroke & 1.009120 & 0.813787 & 1.251339 & 0.934 \\
\hline TIA & 0.877714 & 0.741751 & 1.038599 & 0.129 \\
\hline Undetermined & 0.812306 & 0.548259 & 1.203519 & 0.300 \\
\hline \multicolumn{5}{|c|}{ Level of neurological deficit measured with NIHSS } \\
\hline No neurological deficit & Reference & 0.991601 & 1.356929 & 0.064 \\
\hline Light neurological deficit & 1.159971 & & & \\
\hline Moderate neurological deficit & 2.047076 & 1.390864 & 3.012889 & 0.000 \\
\hline Severe neurological deficit & 1.960430 & 1.236072 & 3.109273 & 0.004 \\
\hline \multicolumn{5}{|c|}{ Physical disability with Barthel index } \\
\hline Totally independent & Reference & & & \\
\hline Minimally dependent & 0.909896 & 0.661837 & 1.250929 & 0.561 \\
\hline Moderately dependent & 1.270401 & 1.096781 & 1.471505 & 0.001 \\
\hline Severely or totally dependent & 1.519167 & 1.259055 & 1.833018 & 0.000 \\
\hline \multicolumn{5}{|l|}{ Previous myocardial infarction } \\
\hline No & Reference & & & \\
\hline Yes & 1.087153 & 0.903138 & 1.308661 & 0.377 \\
\hline Observation time (days) & 0.999009 & 0.997970 & 1.000050 & 0.062 \\
\hline
\end{tabular}

Number of observations $=667$.

Log likelihood $=-9281.635433$

$\mathrm{AlC}^{*}=27.87897$

$B C^{* *}=-4233.279$

* Akaike information criterion.

** Bayesian information criterion.

disability and level of neurological deficit. Observed costs for haemorrhagic events were the highest among different forms of stroke, although this variable did not explain costs variability in the regression model. Direct costs for haemorrhagic stroke patients in the first year after the event were quite low if compared with those of other countries. Dodel et al., in their analysis of subarachnoid hemorrhage in Germany reported an annual direct cost of $€ 22,482$, most of which (92\%) covered by health insurance [35]. Cost composition and evolution of overall management costs at 1, 2, 3 years suggest two important aspects. First, inpatient management and rehabilitation represent the main cost driver (about 90\% of direct costs at year 1). Post-event healthcare interventions (pharmacological treatment and follow up visits) do not seem requiring significant amount of resources.
Second, the comparison between costs at years 1, and costs at year 2 and 3, clearly suggested that most of the healthcare expenditure is concentrated in the first months after the acute event. This aspect highlights the enormous importance, for our healthcare service, to invest more in prevention. In particular, life-style modifications and pharmacological interventions on selected, at high-risk populations should be intensified. In our analysis, we retrospectively observed the usage of certain drugs preventing $\mathrm{CV}$ events in our sample population. As example, only $41 \%$ and $15 \%$ of the sample received an anti-thrombotic therapy and lipid-lowering treatment before the index date, respectively.

Previous experiences of stroke cost of illness studies showed a certain variability of results, maybe due to the different methodological approaches adopted. However, 


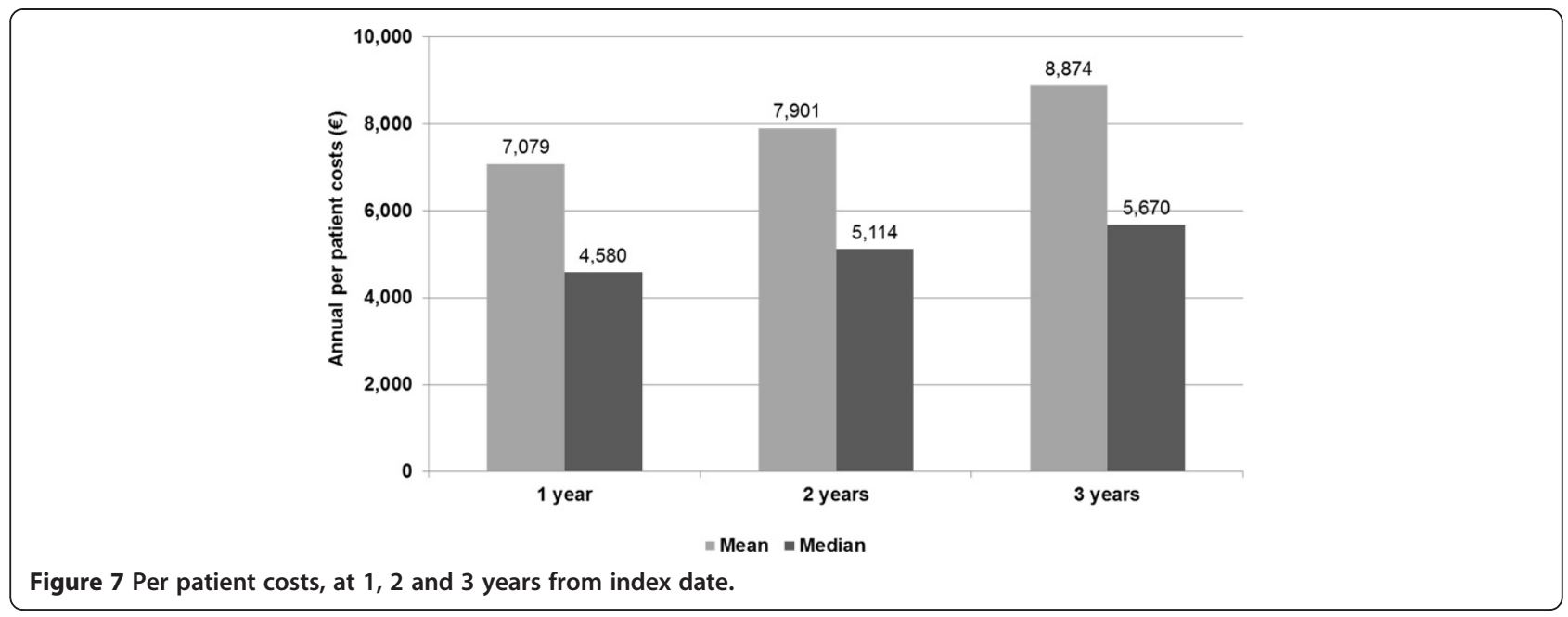

costs estimated in the present study $(€ 8,498$ per patient per year of observation), however are lower, but somehow comparable to previous findings (Gerzeli et al. [20], €6,111 for direct healthcare costs in the first 180 days after stoke), especially considering that: 1) our sample also included patients with TIA, consuming less resources than patients with stroke; 2) distribution of costs is not homogeneous over the first year, with most resources consumed during the first months after the acute episode; 3 ) determination of attributable costs is subject to expert judgment and therefore can differ across studies. Moreover, other international studies found similar trends for long term care of stroke patients [9]. The cost difference between cardioembolic stroke and TIA was also found by Winter et al., in their recent work [36]. The same authors also highlight the acute stroke care as the most relevant cost contributor in management of stroke patients.

The present study shows some limitation regarding the assessment of rehabilitation costs, which could not be break-downed from hospital costs through our informative sources. Therefore these costs were included in the analyses, but we were not able to determine their impact on the overall healthcare expenditure. The analysis of SDO [37] (Hospital Discharge Forms) highlights that LOS (length of stay) of certain patients was longer than 2 weeks, suggesting that those patients were likely moved from the neurology ward to the rehabilitation ward to initiate physiotherapy programs. However, we did not have additional information to estimate the amount of days spent in each of the two wards. The second limitation is due to the choice of including only costs being directly attributable to the cerebrovascular event with high level of evidence. As example, we included in the cost measurements only post-event hospitalizations for cardiocerebrovascular events and evaluated drug expenditure for therapies used in cardio-cerebrovascular prevention. Direct costs could have been slightly underestimated; however we preferred to maintain this conservative approach rather than including costs attributable to other underlying causes. Third, this analysis does not capture indirect costs, which are relevant in stroke [35], but for which a different study approach (mainly based on perspective data) should be adopted.

Our analysis, focused on Region Valle d'Aosta, does not provide any cost comparison among Italian regions. Further research should be oriented to replicate and improve this methodological approach and compare costs by geographical area. A recent study from Frolich et al. [38] highlights large difference of costs when different healthcare systems are compared to each other. In this case, cost differences may be also attributed to different methodological approach. However, we have reason to believe that minor differences would exist among Italian regions, due to a quite standardized hospital care management and a similar access to medical therapies in the different regions.

In conclusion, integrating clinical and administrative data, whereas applicable, seems extremely powerful to obtain reliable and useful information to support evidence-based healthcare programs. Moreover, it permits to retrospectively analyze data in a fast and not expensive way. We believe that this approach, if further refined, will be increasingly exploited by our policy makers in the future.

\section{Competing interests}

The study was sponsored by Pfizer Italy. Simon-Kucher and Partners received grant from Pfizer Italy to participate in the study, contribute to the analysis and draft the manuscript. EB, GC, PT, MVM, GDF declare they have no competing interests and have not received grants or funding to participate in the study. At the time of study conduction, GF was a full-time employee of Simon-Kucher and Partners and received a salary from Simon-Kucher and Partners. GF was previously a full employee of Pfizer Italy (May 2004-October 2008). At the time of study conduction, LS was a full-time employee of Pfizer Italy and received a salary from Pfizer Italy. CN is a full-time employee of Simon-Kucher and Partners and receives a salary from Simon-Kucher and Partners. 


\section{Authors' contributions}

EB, GC, PT, LS, GF and CN participated in the study design and approved the final version of the present article. MVM managed data extraction, data cleaning and record linkage of the different databases used in the analysis. MVM and GF performed statistical analysis. EB, GC, PT, LS and CN supervised statistical analysis. All authors contributed to interpretation of analysis results. EB, GC, PT and GF wrote the manuscript for scientific publication. LS, GDF, CN reviewed the final content of the manuscript. EB, GC, LS and GF coordinated the overall analysis project. All authors read and approved the final manuscript.

\section{Author details}

${ }^{1}$ Department of Neurology, Regional Hospital of Aosta Valley, Aosta, Italy. ${ }^{2}$ Department of Statistics, Regional Hospital of Aosta Valley, Aosta, Italy. ${ }^{3}$ Healthcare Direction, AUSL of Aosta Valley, Aosta, Italy. ${ }^{4}$ Department of Outcome Research Pfizer, Rome, Italy. ${ }^{5}$ Scientific Direction, Italian National Research Center on Aging (I.N.R.C.A.), Ancona, Italy. 'Eife Science Division, Simon-Kucher \& Partners, Milan, Italy.

Received: 10 April 2012 Accepted: 23 October 2012

Published: 30 October 2012

\section{References}

1. World Health Organization: Cerebrovascular Disorders (Offset Publications). Geneva: World Health Organization; 1978.

2. Hachinski V: Stroke: the next 30 years. Stroke 2002, 33:1-4

3. World Health Organization: The World Health Report 1999. Geneva: WHO; 1999.

4. Murray CJL, Lopez AD: Global mortality, disability and the contribution of risk factors. Global burden of the disease study. Lancet 1997, 349:1436-1442.

5. Mackay J, Mensah G: Atlas of Heart Disease and Stroke. Geneva: World Health Organization; 2004

6. World Health Organization: The Atlas of Heart Disease and Stroke. Available at www.who.int/cardiovascular_diseases/resources/atlas.

7. Rosamond W, Flegal K, Furie K, Go A, Greenlund K, Haase N, Hailpern SM, Ho M, Howard V, Kissela B, Kittner S, Lloyd-Jones D, McDermott M, Meigs J, Moy C, Nichol G, O'Donnell C, Roger V, Sorlie P, Steinberger J, Thom T, Wilson M, Hong Y: Heart disease and stroke statistics- 2008 update: a report from the American Heart Association Statistics Committee and Stroke Statistics Subcommittee. Circulation 2008, 117:e25-e146.

8. Brain Basics: Preventing Stroke". National Institute of Neurological Disorders and Stroke. http://www.ninds.nih.gov/disorders/stroke/preventing_stroke. htm. Retrieved 2009-10-24

9. Demaerschalk BM, Hwang HM, Leung G: US cost burden of ischemic stroke: a systematic literature review. Am J Manag Care 2010, 16(7):525-533.

10. Payne KA, Huybrechts KF, Caro JJ, Craig Green TJ, Klittich WS: Long term cost-of-illness in stroke: an international review. Pharmacoeconomics 2002, 20:813-825

11. Caro JJ, Huybrechts KF, Kelley HE: Predicting treatment costs after acute ischemic stroke on the basis of patient characteristics at presentation and early dysfunction. Stroke 2001, 32:100-106.

12. Evers SM, Struiis JN, Ament AJ, Van Genugten ML, Jager JC, Van Den Bos GA International comparison of stroke cost studies. Stroke 2004, 35:1209-1215.

13. Caro JJ, Huybrechts KF, Duchesne I: Management patterns and costs of acute ischemic stroke: an international study. For the Stroke Economic Analysis Group. Stroke 2000, 31:582-590.

14. Terént A, Marké LA, Asplund K, Norrving B, Jonsson E, Wester PO: Costs of stroke in Sweden: a national perspective. Stroke 1994, 25:2363-2369.

15. Saka O, McGurie A, Wolfe C: Cost of stroke in the United Kingdom. Age Ageing 2009, 38:27-32.

16. Ghatnekar O, Persson U, Glader E, Terent A: Cost of stroke in Sweden: An incidence estimate. Int J Technol Assess Health Care 2004, 20:3:375-380.

17. Goeree R, Blackhouse G, Petrovic R, Salama S: Cost of stroke in Canada: a 1-year prospective study. J Med Econ 2005, 8(1-4):147-167.

18. Kolominsky-Rabas P, Heuschmann P, Marschall D, Emmert M, Baltzer N, Neundörfer B, Oliver Schöffski O, Krobot K: Lifetime Cost of Ischemic Stroke in Germany: Results and National Projections From a PopulationBased Stroke Registry. Stroke 2006, 37:1179-1183.

19. Cadilhac DA, Carter R, Thrift AG, Helen M: Estimating the long-term costs of ischemic and hemorrhagic stroke for Australia. Stroke 2009, 40:915-921.
20. Gerzeli S, Tarricone R, Zolo P, Colangelo I, Busca MR, Gandolfo C: The economic burden of stroke in Italy. The EcLIPSE Study: Economic Longitudinal Incidence-based Project for Stroke Evaluation. Neurol Sci 2005, 26(2):72-80.

21. Morsanutto A, Mantovani LG, Ros B, De Portu S, Spazzapan D, Tosolini F: Cost and outcomes after first stoke hospital admission: a longitudinal study using administrative databases. Value Health 2005, 8(6):A151.

22. Tarricone R: Cost-of-illness analysis. What room in health economics? Health Policy 2006, 77:51-63.

23. Mahoney Fl, Barthel DW: Functional evaluation: The Barthel Index. Md State Medical J 1965, 14:61-65.

24. Brott T, Adams HP Jr, Olinger CP, Marler JR, Barsan WG, Biller J, Spilker J, Holleran R, Eberle R, Hertzberg V, Rorick M, Moomaw CJ, Walker M: Measurements of acute cerebral infarction: a clinical examination scale. Stroke 1989, 20:964-970.

25. World Health Organization: Manual of the international statistical classification of diseases, injuries, and causes of death, Volume 1. Geneva: World Health Organization; 1977.

26. Mager DE, Cox ER: Relationship between generic and preferred-brand prescription copayment differentials and generic fill rate. Am J Manag Care 2007, 13(6 Pt 2):347-352.

27. Ghate SR, Biskupiak J, Ye X, Kwong WJ, Brixner DI: All-cause and bleeding related health care costs in warfarin-treated patients with atrial fibrillation. J Manag Care Pharm 2011, 17(9):672-684.

28. Suh DC, Nelson WW, Choi JC, Choi I: Risk of hemorrhage and treatment costs associated with warfarin drug interactions in patients with atrial fibrillation. Clin Ther 2012, 34(7):1569-1582.

29. Schwarzkopf L, Menn P, Leidl R, Wunder S, Mehlig H, Marx P, Graessel E, Holle R: Excess costs of dementia disorders and the role of age and gender - an analysis of German health and long-term care insurance claims data. BMC Health Serv Res 2012, 12:165.

30. Song X, Zhao Z, Barber B, Gregory C, Cao Z, Gao S: Cost of illness in patients with metastatic colorectal cancer. J Med Econ 2011, 14(1):1-9.

31. Mantovani LG, Morsanutto A, Tosolini F, Mustacchi G, Esti R, Belisari A, De Portu S: The burden of renal cell cancer: A retrospective longitudinal study on occurrence, outcomes and cost using an administrative claims database. EJC Supplements 2008, 6(14):46-51.

32. Birnbaum H, Leong S, Oster E, Kinchen $K$, Sun P: Cost of stress urinary incontinence: a claims data analysis. Pharmacoeconomics 2004, 22(2):95-105.

33. Simoni-Wastila L, Blanchette CM, Qian J, Yang HW, Zhao L, Zuckerman $\mathrm{H}_{\text {, }}$ Pak GH, Silver H, Dalal AA: Burden of chronic obstructive pulmonary disease in Medicare beneficiaries residing in long-term care facilities. Am J Geriatr Pharmacother 2009, 7(5):262-270.

34. Prescott J, Factor S: Descriptive analysis of the direct medical costs of multiple sclerosis in 2004 using administrative claims in a large nationwide database. J Manag Care Pharm JMCP 2007, 13:1.

35. Dodel R, Winter Y, Ringel F, Spottke A, Gharevi N, Müller I, Klockgether T, Schramm J, Urbach $\mathrm{H}$, Meyer B: Cost of illness in subarachnoid hemorrhage: a German longitudinal study. Stroke 2010, 41(12):2918-2923.

36. Winter Y, Wolfram C, Schaeg M, Reese JP, Oertel WH, Dodel R, Back T: Evaluation of costs and outcome in cardioembolic stroke or TIA. J Neurol 2009, 256(6):954-963.

37. La Scheda di dimissione ospedaliera. http://www.salute.gov.tt/ ricoveriOspedalieri/.

38. Frolich A, Schiotz ML, Strandberg-Larsen M, Hsu J, Krasnik A, Diderichsen F, Bellows J, Sogaard J, White K: A retrospective analysis of health systems in Denmark and Kaiser Permanente. BMC Health Serv Res 2008, 8:252.

doi:10.1186/1472-6963-12-372

Cite this article as: Bottacchi et al:: The cost of first-ever stroke in Valle d'Aosta, Italy: linking clinical registries and administrative data. BMC Health Services Research 2012 12:372 